\title{
Easy introduction of maleimides at different positions of oligonucleotide chains for conjugation purposes
}

\author{
Albert Sánchez, Enrique Pedroso and Anna Grandas* \\ Received (in XXX, XXX) Xth XXXXXXXXX 20XX, Accepted Xth XXXXXXXXX 20XX \\ ${ }_{5}$ DOI: 10.1039/b000000x
}

[2,5-dimethylfuran]-protected maleimides were placed at both internal positions and the 3'-end of oligonucleotides making use of solid-phase synthesis procedures. A new phosphoramidite derivative and a new solid support incorporating the protected maleimide moiety were prepared for this purpose. In all cases maleimide deprotection (retro-Diels-Alder reaction) followed by reaction with thiol-containing 10 compounds afforded the target conjugate.

\section{Introduction}

Derivatization of oligonucleotides by covalent attachment of a non-oligonucleotide moiety, usually referred to as conjugation, is a common alternative to improve oligonucleotides performance 15 in biological assays and suitability for therapeutic applications (1). 3'-Modification is known to impart protection to the most ubiquitous nucleases, namely 3'-exonucleases (2), and conjugation often improves oligonucleotides' cell permeation properties.

20 In general there is a rationale on the decision as to which moiety is to be linked to the oligonucleotide chain, but the linking site and the linkage type are most often dictated by the chemically available tools (resins or phosphoramidite derivatives commercially available, derivatives synthesized at the laboratory ${ }_{25}$ carrying out the study, etc.). Even though changes in the constitution of the conjugate will likely have an influence on the outcome of biological assays, there is not much information available on this type of structure-activity correlation.

Indeed, there are reports showing the outcome of such changes. It

30 has been described, for instance, that the immune stimulating properties of conjugates in which a 28 -mer $\beta$-amyloid peptide was attached to an oligonucleotide varied depending on whether the peptide was linked to either the $5^{\prime}$ - or the $3^{\prime}$-end (3). It has also been reported that the stability of thiol-maleimide adducts

35 may vary depending on the "external" environment, such as the presence of inorganic anions (4) or reducing agents (thiols) (5), but also depending on the structure of the conjugate itself (6). In a recent piece of work (6), Junutula and co-workers have shown that the stability and activity of antibody-drug conjugates varies 40 depending on whether the conjugation site is placed in a highly solvent accessible and positively charged local environment, or in a partially accessible and neutral local environment.

In a different context, but also showing the importance of conjugates' constitution, an interesting example is the use of DNA

45 as a ruler (7), which shows that the covalent attachment of peptides to different positions of the chain can provide information on the spatial distribution of protein binding sites ( 7 , see references therein for other examples of applications of complex molecular structures).

${ }_{50}$ Oligonucleotide conjugates can be assembled making use of solid-phase technologies when suitably derivatized building blocks of solid supports are available (8). Convergent solution synthesis is the other alternative. In this case the two moieties to be linked must be derivatized with functional groups ideally ${ }_{55}$ reacting regio- and chemoselectively, exploiting the so-called click chemistry (9). The par excellence click reaction is the $\mathrm{Cu}(\mathrm{I})-$ catalyzed azide-alkyne cycloaddition, but well-performing click reactions can exploit other functional groups as well. Maleimides are examples of useful functional units, since they can be 60 involved in two different click reactions, the Michael-type reaction with thiols and the Diels-Alder cycloaddition.

For many years the most common alternative for the derivatization of oligonucleotides with a maleimide has been the reaction, in solution, of bifunctional compounds incorporating a ${ }_{65}$ carboxylic acid and a maleimide with the amine group of aminoderivatized oligonucleotides (10). The problem with this methodology is that amide formation does not always take place in high yield. Yet, attachment of the maleimide-containing bifunctional compound to amino-derivatized resin-linked 70 oligonucleotides is not an alternative, because the ammonia treatment that removes oligonucleotide protecting groups degrades the maleimide (11).

Solid-phase assembly is only possible provided that the maleimide is protected and remains stable to the ammonia 75 deprotection treatment. We have recently described that maleimide building blocks fulfilling this requirement can be obtained by reaction with 2,5-dimethylfuran, followed by removal of the ammonia-labile endo adduct (12). Bifunctional compounds containing a protected maleimide (exo adduct) and 80 either phosphoramidite (1) or carboxyl (2) groups (Figure 1) can be used for the on-resin assembly of maleimido-oligonucleotides. Compound 1 has two advantages over 2. On the one hand, that it can be incorporated after elongation of the oligonucleotide chain 
using the same chemistry as for all nucleosides. On the other, it is not necessary to assemble amine-derivatized resin-linked oligonucleotides to which $\mathbf{2}$ must be coupled by forming an amide bond. Even though this type of reactions takes place on a 5 solid matrix, which allows large excesses of the activated carboxyl-containing species to be added, coupling yields have been described as poorly reproducible and not always fully satisfactory (13).

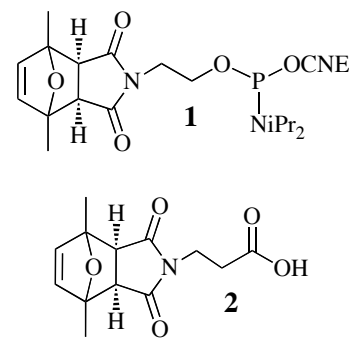

Figure 1. Structures of the [protected maleimido]-containing derivatives previously used in the synthesis of maleimido-oligonucleotides.

Incorporation of a protected maleimido unit after oligonucleotide elongation using standard nucleoside-3'-phosphoramidite derivatives, followed by deprotection with ammonia and heating 15 to provide the free maleimide (retro-Diels-Alder reaction), affords 5'-maleimido-oligonucleotides. Chain elongation with nucleoside-5'-phosphoramidites might allow 3'-maleimidooligonucleotides to be assembled, but these derivatives are much more expensive than standard nucleoside-3'-phosphoramidite.

${ }_{20}$ Since, as described above, it is important to have access to conjugates with different structures, we decided to prepare a new phosphoramidite building block allowing the maleimide unit to be placed at internal positions of the oligonucleotide sequence (in fact at any position of the chain), and a new solid matrix 25 incorporating the protected maleimide moiety that is suitable for the synthesis of 3'-maleimido-oligonucleotides making use of 3'phosphoramidite derivatives. In this manuscript we describe their synthesis and their use in the preparation of maleimidooligonucleotides. These maleimido-oligonucleotides were reacted 30 with thiols to assess the functionality of the maleimides.

\section{Results and discussion}

The synthesis of building block 5 and solid support 7 is summarized in Scheme 1. Both incorporate a DMT-protected hydroxyl to allow for further elongation of the chain. The two ${ }_{35}$ compounds 5 and $\mathbf{7}$ derive from common precursor $\mathbf{4}$, which has the advantage that preparation of $\mathbf{4}$ provides a stock of a product from which either $\mathbf{5}$ or $\mathbf{7}$ can be obtained in one or two steps.

For the synthesis of $\mathbf{4}$, the amino group of L-serinol, more nucleophilic than the hydroxyl groups, was derivatized first.

40 Reaction between $\mathbf{2}$ (exo adduct), a carbodiimide and pentafluorophenol provided the pentafluorophenyl ester of $\mathbf{2}$, and this active ester reacted with L-serinol to form the amide with no need to protect the hydroxyl groups. Then, one of the hydroxyl groups of the resulting compound (3) was protected by reaction ${ }_{45}$ with DMT-Cl. Use of a smaller amount of DMT-Cl (0.9 equiv) with respect to $\mathbf{3}$ facilitated formation and isolation of $\mathbf{4}$ as the main product. Phosphitylation of $\mathbf{4}$ afforded phosphoramidite $\mathbf{5}$, while reaction of $\mathbf{4}$ with succinic anhydride and incorporation of the resulting 6 onto LCAA-CPG provided support 7.

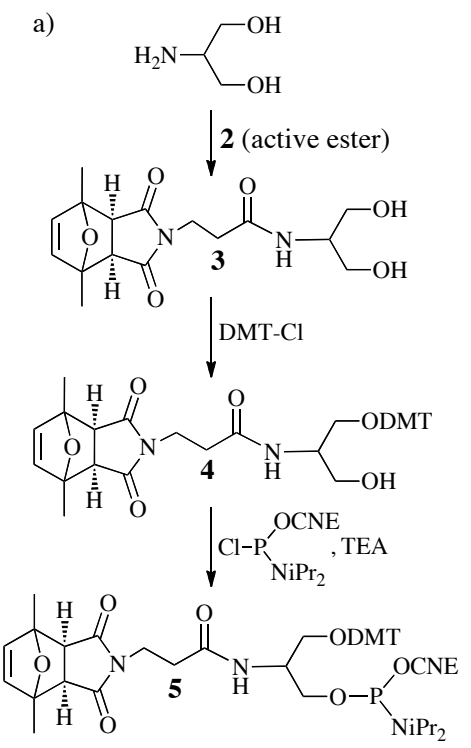

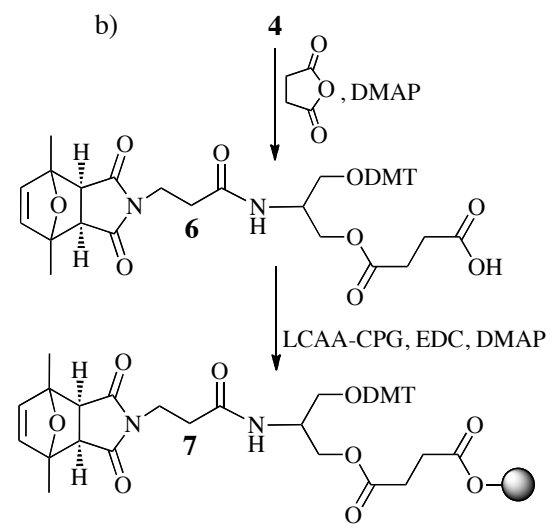

Scheme 1. Synthesis of [protected maleimido]-derivatized building block 5 (a) and solid support 7 (b).

Derivatives 5 and 7 were used in the synthesis of two maleimidooligonucleotides, 9 and 12 (Scheme 2). In both cases chain ${ }_{55}$ elongation proceeded smoothly, showing that the two derivatives behaved as standard building blocks. The [protected maleimido]oligonucleotides (8 and 11) obtained after reaction with ammonia at room temperature were purified by HPLC (Figure 2) and characterized by mass spectrometry.

60 Maleimide deprotection was carried out using the method that had performed better in our previous work $(12,14)$, namely heating a suspension of the oligonucleotide in anh. toluene at 90 ${ }^{\circ} \mathrm{C}$ for $4 \mathrm{~h}$. Maleimide deprotection yields were above $90 \%$, as assessed by HPLC analysis of the crudes (Figure 3). 
a)

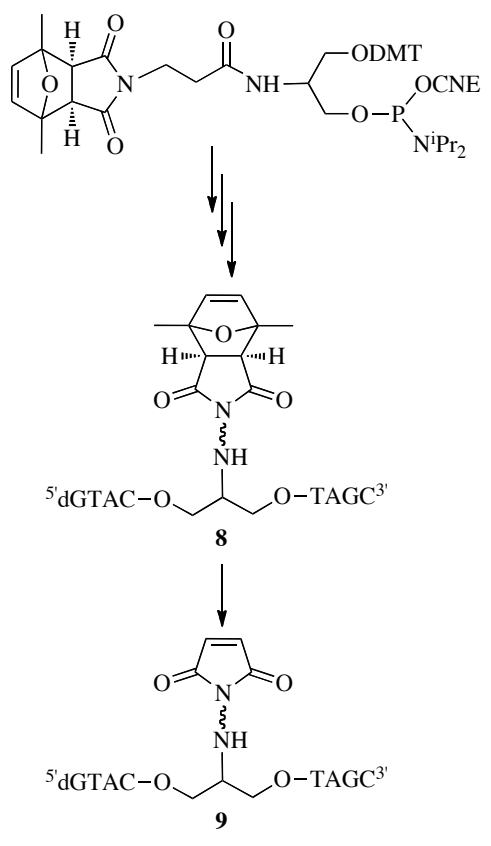

b)

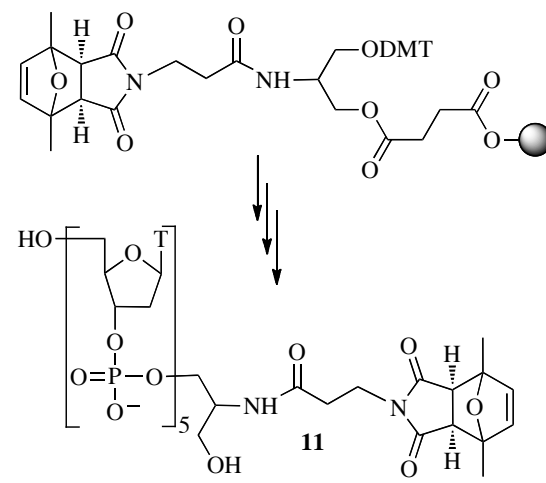

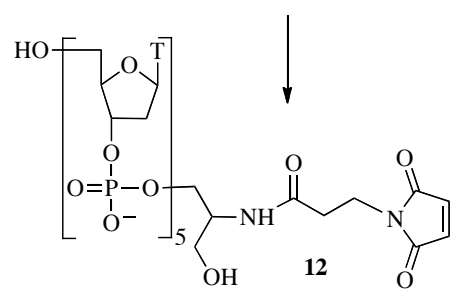

$$
12+\text { biotin- } \mathrm{SH} \rightarrow \mathbf{1 3}
$$$$
12+\text { glutathione } \rightarrow 14
$$

Scheme 2. Synthesis of [protected maleimido]-oligonucleotides, maleimido-oligonucleotides and conjugates.

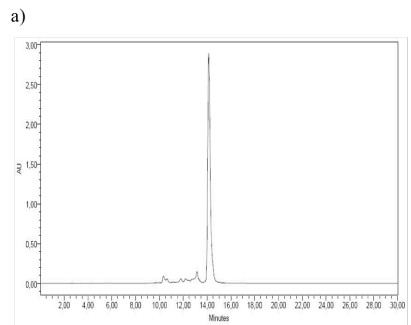

b)

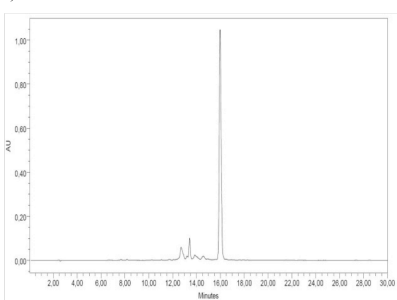

Figure 2. Crude ${ }^{5}$ dGTAC-[protected maleimido monomer]-TAGC 8 (a) and $\mathrm{dT}_{5-}{ }^{3}$ [protected maleimide] 11 (b).

a)

b)
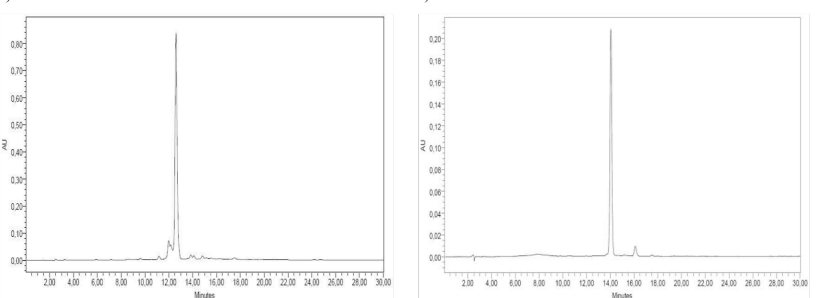

Figure 3. Crude ${ }^{5}$ dGTAC-[maleimido monomer]-TAGC 9 (a) and $\mathrm{dT}_{5}$ '[maleimide] 12 (b).

Finally, it was verified that reversal of the Diels-Alder dimethylfuran-maleimide cycloadduct afforded oligonucleotides with appending fully reactive maleimides. For this purpose, maleimido-oligonucleotides $\mathbf{9}$ and $\mathbf{1 2}$ were reacted with thiol15 containing compounds, as shown in Scheme 2. Michael-type thiol-maleimide reactions yielded the target conjugates, as confirmed by mass spectrometric analysis of the product corresponding to the main peak of the HPLC trace of the crude (Figure 4). The maleimide moiety linked to the 3'-end of the 20 oligonucleotide thoroughly reacted with two primary thiols, those of biotin-SH and glutathione, to yield conjugates $\mathbf{1 3}$ and $\mathbf{1 4}$, respectively (Figure 4b,c). Likewise, reaction between the maleimide placed at an internal position and the secondary thiol of thiocholesterol, somehow more demanding because the 25 reaction groups were more hindered, cleanly furnished conjugate 10 (Figure 4a).

a)

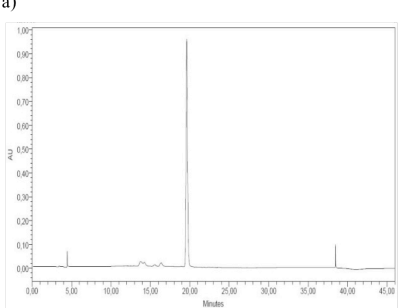

b)

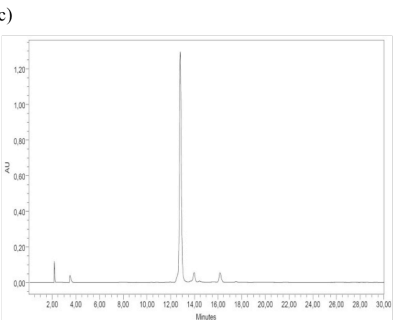

Figure 4. Crude conjugates 10 (a), 13 (b) and 14 (c)

\section{Conclusions}

30 In summary, a phosphoramidite derivative and a solid support incorporating 2,5-dimethylfuran-protected maleimide moieties were synthesized from a common precursor (4), obtained from Lserinol. Both were satisfactorily used in the preparation of maleimido-oligonucleotides that subsequently underwent addition 35 of thiols, thus proving that maleimide deprotection affords reactive maleimides. This new building block and resin expand the repertoire of possibilities allowing the derivatization of oligonucleotides at different positions, and thus give access to differently decorated oligonucleotide chains. 


\section{Experimental}

\section{General}

Nucleoside phosphoramidites ( $\mathrm{dA}^{\mathrm{Pac}}, \mathrm{dC}^{\mathrm{Ac}}, \mathrm{dG}^{\mathrm{Dmf}}$ and $\left.\mathrm{dT}\right), \mathrm{CPG}$ supports, and oligonucleotide synthesis reagents were from either 5 Link Technologies, Glen Research Corporation or Applied Biosystems. [Protected maleimido]-propanoic acid (2, exo adduct) was prepared as previously described (12). Biotin-SH was prepared following described procedures (14). Glutathione and thiocholesterol were from Sigma-Aldrich. Acid-free DCM

10 was obtained by filtration through basic alumina.

TLC was carried out on silica gel plates $60 \mathrm{~F}_{254}$ from Merck. Samples were lyophilized in a FreezeMobile Virtis instrument. The amount of free thiols in thiol-containing compounds was quantified by the Ellman test, as described in the Supporting 15 Information of reference 12.

Oligonucleotide synthesis. Oligonucleotide chains were assembled in a $3400 \mathrm{ABI}$ automatic synthesizer at the $1 \mu \mathrm{mol}$ scale, using standard phosphoramidite synthesis cycles. Phosphoramidite $\mathbf{5}$ and solid support $\mathbf{7}$ were used as any standard 20 reagent. After chain elongation, treatment with concd. aq. ammonia at room temperature $(1 \mathrm{~h}$ in case of homo-dT oligomer 11; $8 \mathrm{~h}$ when all the bases were present) removed protecting groups from the oligonucleotide. After filtration and washing, ammonia was evaporated under reduced pressure, and the sample 25 lyophilized. Oligonucleotides were purified by reversed-phase HPLC, quantified by UV spectroscopy $(\lambda=260 \mathrm{~nm})$, and characterized by mass spectrometry.

Maleimide deprotection by heating in toluene. The [protected maleimido]-containing oligonucleotide was dried by

${ }_{30}$ coevaporation with anh. toluene (3-4 $\times$ ), and a new batch of anh. toluene was added (the amount that would be required to obtain a $25 \mu \mathrm{M}$ solution). The mixture was heated $90^{\circ} \mathrm{C}$, toluene was removed under reduced pressure, and the crude was dissolved in water for HPLC analysis and mass spectrometric characterization.

${ }_{35}$ The crude was typically used at the subsequent conjugation step without any purification.

General procedure for Michael-type conjugation reactions. Aliquots of aqueous solutions containing the required amounts of maleimido-containing oligomer and the corresponding thiol40 containing compound (5 to 10 -fold molar excess) were mixed, and the mixture was diluted with $0.5 \mathrm{M}$ triethylammonium acetate, $\mathrm{pH}=7.8-7.9$ (final concentration of oligomer: 50-150 $\mu \mathrm{M})$. The mixture was stirred at room temperature under an $\mathrm{Ar}$ atmosphere. Reaction crudes were analyzed by HPLC. ${ }_{45}$ Conjugates were purified by HPLC and characterized by MALDI-TOF MS.

Synthesis of conjugate 10: thiocholesterol (not soluble in water) was dissolved in THF, and the reaction was carried out in a $3: 2$ $(\mathrm{v} / \mathrm{v}) 0.5 \mathrm{M}$ triethylammonium acetate $(\mathrm{pH}=7.8) / \mathrm{THF}$ mixture.

HPLC. Reversed-phase HPLC analysis and purification was performed using analytical and semipreparative Waters or Shimadzu systems. Analysis and purification conditions were:

Oligonucleotide analysis conditions: Kromasil C18 column (10 ${ }_{55} \mu \mathrm{m}, 100 \AA, 250 \times 4.0 \mathrm{~mm}$ ) from Akzo Nobel; solvent A: $0.05 \mathrm{M}$ triethylammonium acetate, solvent $\mathrm{B}: \mathrm{H}_{2} \mathrm{O} / \mathrm{ACN}$ 1:1 (v/v), gradient from 5 to $60 \%$ of $\mathrm{B}$ in $30 \mathrm{~min}$, flow: $1 \mathrm{~mL} / \mathrm{min}$, detection wavelength: $254 \mathrm{~nm}$.

Oligonucleotide purification conditions (semipreparative

60 scale): Jupiter $\mathrm{C} 18$ column $(10 \mu \mathrm{m}, 300 \AA, 250 \times 10.0 \mathrm{~mm})$ from Phenomenex, solvent A: $0.1 \mathrm{M}$ triethylammonium acetate, solvent $\mathrm{B}: \mathrm{H}_{2} \mathrm{O} / \mathrm{ACN} 1: 1(\mathrm{v} / \mathrm{v})$, gradient from 5 to $60 \%$ of $\mathrm{B}$ in $30 \mathrm{~min}$, flow: $3 \mathrm{~mL} / \mathrm{min}$, detection wavelength: $260 \mathrm{~nm}$.

Cholesterol-containing conjugate analysis and purification ${ }_{65}$ conditions: Kromasil C4 column $(10 \mu \mathrm{m}, 100 \AA \AA, 250 \times 4.6 \mathrm{~mm})$ from Teknokroma, solvent A: $0.05 \mathrm{M}$ triethylammonium acetate $(\mathrm{pH}=7.0)$, solvent $\mathrm{B}$ : acetonitrile, flow: $1 \mathrm{~mL} / \mathrm{min}$, detection wavelength: $254 \mathrm{~nm}$. After injection of the samples, the column was eluted for $5 \mathrm{~min}$ with $10 \%$ of $\mathrm{B}$, followed by gradient from 7010 to $90 \%$ of B in $25 \mathrm{~min}$. Subsequently, the column was eluted for 10 min with $90 \%$ of $\mathrm{B}$.

Mass spectrometry. MALDI-TOF mass spectra were recorded on a 4800 Plus ABSciex instrument using reflector. Oligonucleotide and conjugates analysis conditions: 1:1 (v/v) 75 2,4,6-trihydroxyacetophenone/ammonium citrate (THAP/CA), negative mode. ESI (low and high resolution) mass spectra were obtained using an LC/MSD-TOF spectrometer from Agilent Technologies.

Synthesis of the [protected maleimido]-containing monomer 5 80 and solid support 7.

[Protected maleimido]-diol 3. 2,5-Dimethylfuran-protected 3maleimidopropanoic acid (2, $300 \mathrm{mg}, 1.13 \mathrm{mmol})$, DIPC (177 $\mu \mathrm{L}, 1.13 \mathrm{mmol})$ and pentafluorophenol $(210 \mathrm{mg}, 1.13 \mathrm{mmol})$ were dissolved in anh. DMF ( $N, N$-dimethylformamide). After 30 $85 \mathrm{~min}$ stirring, serinol $(90 \mathrm{mg}, 0.942 \mathrm{mmol})$ was added to the mixture containing the activated form of the carboxyl group, and left to react at room temperature under an Ar atmosphere for 12 h. The solvent was removed under reduced pressure, and the resulting crude was purified by silica gel column chromatography 90 eluting with DCM (dichloromethane) and increasing amounts of $\mathrm{MeOH}$ (from 0 to $10 \%$ ). 3 was obtained as a white solid (318 $\mathrm{mg}$, quantitative yield).

TLC (DCM/MeOH 4:1): $\mathrm{Rf}=0.32 ;{ }^{1} \mathrm{H} \mathrm{NMR}\left(\mathrm{CDCl}_{3}, 400 \mathrm{MHz}\right)$ : $\delta 6.30(\mathrm{~s}, 2 \mathrm{H}), 3.86-3.82(\mathrm{~m}, 6 \mathrm{H}), 3.78(\mathrm{td}, J=7.0,3.8 \mathrm{~Hz}, 1 \mathrm{H})$, $953.02(\mathrm{t}, J=6.0 \mathrm{~Hz}, 2 \mathrm{H}), 2.84(\mathrm{~s}, 2 \mathrm{H}), 2.57$ (t, $J=6.0 \mathrm{~Hz}, 2 \mathrm{H})$, $1.70(\mathrm{~s}, 6 \mathrm{H}) ;{ }^{13} \mathrm{C} \mathrm{NMR}\left(\mathrm{CDCl}_{3}, 101 \mathrm{MHz}\right): \delta 174.8,159.1,140.9$, 87.9, 64.4, 52.6, 52.5, 35.6, 34.5, 16.0 ppm; HRMS (ESI, positive mode): $m / z$ 339.1539, calcd. for $\mathrm{C}_{16} \mathrm{H}_{23} \mathrm{~N}_{2} \mathrm{O}_{6}[\mathrm{M}+\mathrm{H}]^{+} 339.1551$, $m / z$ 361.1374, calcd. for $\mathrm{C}_{16} \mathrm{H}_{22} \mathrm{~N}_{2} \mathrm{O}_{6} \mathrm{Na}[\mathrm{M}+\mathrm{Na}]^{+} 361.1370, \mathrm{~m} / z$ 100 699.2834, calcd. for $\mathrm{C}_{32} \mathrm{H}_{44} \mathrm{~N}_{4} \mathrm{O}_{12} \mathrm{Na}[2 \mathrm{M}+\mathrm{Na}]^{+} 699.2848$.

DMT-O-[Protected maleimido]-diol 4. Compound $3(318 \mathrm{mg}$, $0.94 \mathrm{mmol})$ and DMT-Cl (293 $\mathrm{mg}, 0.85 \mathrm{mmol})$ was dissolved in anh. pyridine $(10 \mathrm{~mL})$. After $15 \mathrm{~h}$ stirring at room temperature under an Ar atmosphere, pyridine was removed under reduced ${ }_{105}$ pressure. The resulting crude was purified by silica gel column chromatography eluting with hexanes/DCM 1:1, increasing amounts of DCM (until $100 \%$ ) and DCM/AcOEt mixtures (up to 7:3) always with triethylamine (4\%). The fractions containing the desired product were pooled, and after removing the solvent 110 in vacuo were coevaporated with $\mathrm{ACN}$ to eliminate triethylamine traces, dissolved in acid-free DCM $(25 \mathrm{~mL})$ and washed with brine $(3 \times 25 \mathrm{~mL})$. The organic phase was dried over anh. $\mathrm{Na}_{2} \mathrm{SO}_{4}$ and taken to dryness. A white solid $(4,410 \mathrm{mg}, 75 \%$ yield) was obtained.

${ }_{115} \mathrm{TLC}(\mathrm{DCM} / \mathrm{MeOH} 19: 1): \mathrm{Rf}=0.33 ;{ }^{1} \mathrm{H} \mathrm{NMR}\left(\mathrm{CDCl}_{3}, 400 \mathrm{MHz}\right.$ 
$\left.\mathrm{CDCl}_{3}\right): \delta 7.39-7.19(\mathrm{~m}, 9 \mathrm{H}), 6.83(\mathrm{~d}, J=8.9 \mathrm{~Hz}, 4 \mathrm{H}), 6.28(\mathrm{~s}$, $2 \mathrm{H}), 5.98(\mathrm{~d}, J=7.6 \mathrm{~Hz}, 1 \mathrm{H}), 4.03(\mathrm{tt}, J=9.2,4.7 \mathrm{~Hz}, 1 \mathrm{H}), 3.84$ (dd, $J=13.8,7.3 \mathrm{~Hz}, 2 \mathrm{H}), 3.79(\mathrm{~s}, 6 \mathrm{H}), 3.70$ (dd, $J=13.7,7.0$ $\mathrm{Hz}, 2 \mathrm{H}), 3.29$ (qd, $J=9.7,4.8 \mathrm{~Hz}, 2 \mathrm{H}), 2.78(\mathrm{dd}, J=1.4 \mathrm{~Hz}, 2 \mathrm{H})$, $52.47(\mathrm{t}, J=6.6 \mathrm{~Hz}, 2 \mathrm{H}) 1.67(\mathrm{~s}, 6 \mathrm{H}) ;{ }^{13} \mathrm{C} \mathrm{NMR}\left(\mathrm{CDCl}_{3}, 101\right.$ MHz): $\delta 174.8,170.1,158.7,144.6,141.0,135.7,130.1,128.1$, 127.1, 113.4, 87.8, 86.7, 63.6, 63.2, 55.4, 52.5, 51.7, 35.2, 34.2, 29.8, $16.0 \mathrm{ppm}$; HRMS (ESI, positive mode): $\mathrm{m} / \mathrm{z}$ 663.2672, calcd. for $\mathrm{C}_{37} \mathrm{H}_{40} \mathrm{~N}_{2} \mathrm{O}_{8} \mathrm{Na}[\mathrm{M}+\mathrm{Na}]^{+}$663.2677, m/z 1303.5430, 10 calcd. for $\mathrm{C}_{74} \mathrm{H}_{80} \mathrm{~N}_{4} \mathrm{O}_{16} \mathrm{Na}[2 \mathrm{M}+\mathrm{Na}]^{+} 1303.5462$.

DMT- $O$-[Protected maleimido]-diol phosphoramidite 5 . Compound 4 (225 mg, $0.35 \mathrm{mmol})$ was dried by coevaporation with anh. ACN $(3 \times 1 \mathrm{~mL})$, and dissolved in anh. DCM $(1 \mathrm{~mL})$. Triethylamine (1 $\mathrm{mL}, \quad 7.17 \quad \mathrm{mmol})$ and (215 cyanoethoxy)chloro(diisopropylamino)-phosphine (83 $\mu \mathrm{L}, 0.37$ mmol) was added, and the mixture was reacted at room temperature for $1 \mathrm{~h}$ under an Ar atmosphere. This was followed by addition of DCM $(25 \mathrm{~mL})$ and extraction with $5 \% \mathrm{NaHCO}_{3}(2$ $\times 25 \mathrm{~mL})$ and brine $(1 \times 25 \mathrm{~mL})$. The organic phase was dried 20 over $\mathrm{Na}_{2} \mathrm{SO}_{4}$ and the solvent was removed under vacuum, adding ACN to prevent the amidite solution from being too rich in TEA. Phosphoramidite $\mathbf{5}$ was obtained as a white powder after lyophilization from anh. benzene $(270 \mathrm{mg}, 92 \%$ yield; single spot by TLC). This solid was used for the assembly of 25 maleimido-oligonucleotide $\mathbf{8}$ in spite of being slightly impurified with the phosphine hydrolysis product. Attempts to purify $\mathbf{5}$ by silica gel column chromatography were unsuccessful, because the collected fractions were less pure than the material obtained after the work-up.

${ }_{30} \mathrm{TLC}(\mathrm{DCM} / \mathrm{MeOH} 19: 1): \mathrm{Rf}=0.56 ;{ }^{31} \mathrm{P} \mathrm{NMR}\left(\mathrm{CDCl}_{3}, 121.42\right.$ $\mathrm{MHz}$ ): $\delta 148.2,148.0 \mathrm{ppm}$ (plus one signal at $14.2 \mathrm{ppm}$ ); HRMS (ESI, positive mode): $m / z$ 863.3774, calcd. for $\mathrm{C}_{46} \mathrm{H}_{57} \mathrm{~N}_{4} \mathrm{O}_{9} \mathrm{PNa}$ $[\mathrm{M}+\mathrm{Na}]^{+} 863.3755$.

DMT- $O$-[Protected maleimido]-diol hemisuccinate 6. DMAP

$35(3.8 \mathrm{mg}, 0.031 \mathrm{mmol})$ and succinic anhydride $(6.4 \mathrm{mg}, 0.062$ mmol) were added to a solution of alcohol 4 (40 $\mathrm{mg}, 0.062$ $\mathrm{mmol})$ in anh. pyridine $(200 \mu \mathrm{L})$. The mixture was reacted at room temperature, under an $\mathrm{Ar}$ atmosphere, for $15 \mathrm{~h}$, after which time TLC analysis showed that the starting material (4) had been 40 completely consumed. After removing the solvent in vacuo, and coevaporation with $\mathrm{ACN}(3 \times 1 \mathrm{~mL})$, the resulting crude was dissolved in acid-free DCM $(2 \mathrm{~mL})$, and this solution was extracted with a $10 \%$ aqueous citric acid solution $(3 \times 2 \mathrm{~mL})$, water $(1 \times 2 \mathrm{~mL})$, and brine $(1 \times 2 \mathrm{~mL})$. The organic phase was 45 dried over anh. $\mathrm{Na}_{2} \mathrm{SO}_{4}$, and solvent removal under reduced pressure afforded 6 as a whitish solid ( $45 \mathrm{mg}, 98 \%$ yield).

TLC (DCM/MeOH 19:1): $\mathrm{Rf}=0.32 ;{ }^{1} \mathrm{H}$ NMR $\left(\mathrm{CDCl}_{3}, 400\right.$ MHz): $\delta 7.41-7.39$ (m, 2H), 7.28 (dd, $J=8.9,1.4 \mathrm{~Hz}, 6 \mathrm{H}), 7.19$ (dd, $J=18.3,8.1 \mathrm{~Hz}, 1 \mathrm{H}), 6.83(\mathrm{dd}, J=8.9,1.2 \mathrm{~Hz}, 4 \mathrm{H}), 6.29$ (s, $\left.{ }_{50} 2 \mathrm{H}\right), 6.13(\mathrm{~d}, J=8.2 \mathrm{~Hz}, 1 \mathrm{H}), 4.35(\mathrm{~s}, 2 \mathrm{H}), 3.79(\mathrm{~s}, 6 \mathrm{H}), 3.78-$ $3.70(\mathrm{~m}, 2 \mathrm{H}), 3.23(\mathrm{dd}, J=9.1,4.0 \mathrm{~Hz}, 1 \mathrm{H}), 3.10(\mathrm{dd}, J=9.0,6.8$ $\mathrm{Hz}, 1 \mathrm{H}), 2.78(\mathrm{~s}, 2 \mathrm{H}), 2.70-2.60(\mathrm{~m}, 2 \mathrm{H}), 2.60-2.48(\mathrm{~m}, 4 \mathrm{H})$, $2.45-2.38(\mathrm{~m}, 2 \mathrm{H}), 1.67(\mathrm{~d}, J=3.9 \mathrm{~Hz}, 6 \mathrm{H}) ;{ }^{13} \mathrm{C} \mathrm{NMR}\left(\mathrm{CDCl}_{3}\right.$, $101 \mathrm{MHz}): \delta 175.2,174.6,172.3,169.5,158.7,144.7,141.0$, ${ }_{55} 135.9,130.1,129.3,128.2,128.0,127.0,113.3,87.9,86.4,63.6$, $62.0,55.4,52.6,48.5,35.4,34.3,29.8,29.6,29.1,15.9$ ppm; HRMS (ESI, positive mode): $\mathrm{m} / \mathrm{z}$ 763.2833, calcd. for $\mathrm{C}_{41} \mathrm{H}_{44} \mathrm{~N}_{2} \mathrm{O}_{11} \mathrm{Na}[\mathrm{M}+\mathrm{Na}]^{+}$763.2837, $\mathrm{m} / z$ 1503.5780, calcd. for
$\mathrm{C}_{82} \mathrm{H}_{88} \mathrm{~N}_{4} \mathrm{O}_{22} \mathrm{Na}[2 \mathrm{M}+\mathrm{Na}]^{+} 1503.5782$.

${ }_{60}$ DMT-O-[Protected maleimido]-diol-succinyl-LCAA-CPG 7 (15). LCAA-CPG $(100 \mathrm{mg}, 71 \mu \mathrm{mol} / \mathrm{g})$ was introduced in a 2 mL-polyethylene syringe fitted with a polypropylene disc, washed (DCM: $3 \times 2 \mathrm{~mL}, 3 \%$ TCA in DCM: $3 \times 2 \mathrm{~mL}, 20 \%$ TEA in DCM: $5 \times 5 \mathrm{~mL}$, and acid-free DCM: $5 \times 5 \mathrm{~mL}$ ), and 65 thoroughly dried. Compound 6 (21 mg, $0.028 \mathrm{mmol})$, DMAP (2 $\mathrm{mg}, 0.014 \mathrm{mmol})$ and EDC (54 $\mathrm{mg}, 0.28 \mathrm{mmol}$ ) was dissolved in a 70:1 (v/v) mixture $(710 \mu \mathrm{L})$ of anh. pyridine and anh. TEA, respectively, and the resulting solution poured into the syringe containing the LCAA-CPG. The mixture was gently stirred using 70 a shaker under an Ar atmosphere for $3.5 \mathrm{~h}$. The CPG beads were then filtered, washed (pyridine: $10 \mathrm{~mL}, \mathrm{MeOH}: 20 \mathrm{~mL}$, and acidfree DCM: $30 \mathrm{~mL}$ ) and dried. Removal of the DMT group from an aliquot of DMT-O-[protected maleimido propanoyl]- $N$ succinylserinol-LCAA-CPG showed that the solid matrix (7, 75 substitution degree $=31 \mu \mathrm{mol} / \mathrm{g}$ ) was suitable for solid-phase oligonucleotide synthesis. Possible unreacted amines were capped by reaction with a $1: 1(\mathrm{v} / \mathrm{v})$ mixture of the Cap A and Cap $\mathrm{B}$ reagents used at the capping step in solid-phase oligonucleotide synthesis ( $2 \mathrm{~h}$, room temperature), after which time the glass 80 beads were filtered, washed (MeOH: $20 \mathrm{~mL}$, acid-free DCM: 30 $\mathrm{mL}$ ) and dried.

\section{Oligonucleotides and conjugates.}

5'dGTAC-[protected maleimido monomer]-TAGC 8 (87 \% yield in the crude, as assessed by HPLC) was purified by HPLC 85 at the semipreparative scale. Analytical HPLC: $t_{R}=14.2 \mathrm{~min}$ (Figure 2a); MALDI-TOF MS (negative mode): $\mathrm{m} / \mathrm{z} 2807.1$ [M$\mathrm{H}]^{-}$, M calcd. for $\mathrm{C}_{94} \mathrm{H}_{120} \mathrm{~N}_{32} \mathrm{O}_{54} \mathrm{P}_{8} 2808.6$.

$\mathbf{d T}_{5^{-}}{ }^{3}$ [protected maleimide] $\mathbf{1 1}(86 \%$ yield in the crude, as assessed by HPLC) was purified by HPLC at the semipreparative 90 scale. Analytical HPLC: $t_{\mathrm{R}}=16.0 \mathrm{~min}$ (Figure 2b); MALDI-TOF MS (negative mode): $\mathrm{m} / \mathrm{z} 1857.4 \quad[\mathrm{M}-\mathrm{H}]^{-}, \mathrm{M}$ calcd. for $\mathrm{C}_{66} \mathrm{H}_{87} \mathrm{~N}_{12} \mathrm{O}_{41} \mathrm{P}_{5}$ 1858.4.

dGTAC-[maleimido]-TAGC 9 was obtained after deprotection of ${ }^{5}$ dGTAC-[protected maleimide]-TAGC $\mathbf{8}$ as described above 95 (quantitative deprotection as assessed by HPLC of the crude, Figure 3a). Analytical HPLC (gradient from 5 to $60 \%$ of B in 30 $\min$ ): $t_{R}=12.6 \mathrm{~min}$; MALDI-TOF MS (negative mode): $\mathrm{m} / z$ $2711.1[\mathrm{M}-\mathrm{H}]^{-}, \mathrm{M}$ calcd. for $\mathrm{C}_{88} \mathrm{H}_{112} \mathrm{~N}_{32} \mathrm{O}_{53} \mathrm{P}_{8}$ 2712.5. The crude was used without further purification in the conjugation reaction.

$100 \mathbf{d T}_{5^{-}}{ }^{3^{\prime}}$ [maleimide] 12 was obtained after deprotection of $\mathrm{dT}_{5^{-}}$ ${ }^{3}$ '[protected maleimide] 11 as described above (96\% deprotection yield as assessed by HPLC of the crude, Figure 3b). Analytical HPLC: $\mathrm{t}_{\mathrm{R}}=14.1 \mathrm{~min}$; MALDI-TOF MS (negative mode): $\mathrm{m} / \mathrm{z}$ 1761.4 [M-H] $]^{-}, \mathrm{M}$ calcd. for $\mathrm{C}_{60} \mathrm{H}_{79} \mathrm{~N}_{12} \mathrm{O}_{40} \mathrm{P}_{5}$ 1762.3. The crude 105 was used without further purification in the conjugation reactions. Conjugate $10(9+$ thiocholesterol $)$. After stirring the conjugation reaction mixture overnight, the solvent was removed under vacuum, water was added and the insoluble residue was filtered (13 mm Syringe Filter $0.2 \mathrm{~mm}$ PTFE membrane). C18 HPLC 10 analysis of the crude showed virtually complete disappearance of the peak of $\mathrm{T}_{5^{-}}{ }^{3}$ maleimide (9); C4 HPLC trace of the crude is shown in Figure $4 a, t_{R}=19.6 \mathrm{~min}$; MALDI-TOF MS (negative mode): $m / z 3114.2[\mathrm{M}-\mathrm{H}]^{-}, \mathrm{M}$ calcd. for $\mathrm{C}_{115} \mathrm{H}_{158} \mathrm{~N}_{32} \mathrm{O}_{53} \mathrm{P}_{8} \mathrm{~S}$ 3114.8 .

${ }_{115}$ Conjugate 13 (12 + biotin). Conjugation reaction time: 1 h. 95 $\%$; conjugation yield (from the HPLC of the crude, Figure 4b): 95 
$\%$. Analytical HPLC: $\mathrm{t}_{\mathrm{R}}=17.0 \mathrm{~min}$; MALDI-TOF MS (negative mode): $m / z 2064.4[\mathrm{M}-\mathrm{H}]^{-}, \mathrm{M}$ calcd. for $\mathrm{C}_{72} \mathrm{H}_{100} \mathrm{~N}_{15} \mathrm{O}_{42} \mathrm{P}_{5} \mathrm{~S}_{2}$ 2065.4.

Conjugate 14 (12 + glutathione). Conjugation reaction time: $1 \mathrm{~h}$. $596 \%$; conjugation yield (from the HPLC of the crude, Figure 4c): $96 \%$. Analytical HPLC: $t_{R}=12.8 \mathrm{~min} ;$ MALDI-TOF MS (negative mode): $m / z \quad 2068.3 \quad[\mathrm{M}-\mathrm{H}]^{-}, \quad \mathrm{M}$ calcd. for $\mathrm{C}_{70} \mathrm{H}_{96} \mathrm{~N}_{15} \mathrm{O}_{46} \mathrm{P}_{5} \mathrm{~S} 2069.4$.

Acknowledgments. This work was supported by funds from the Ministerio de Ciencia e Innovación (grant CTQ2010-21567-C0201, and the project RNAREG, grant CSD2009-00080, funded under the programme CONSOLIDER INGENIO 2010), and the

${ }_{15}$ Generalitat de Catalunya (2009SGR-208). A. S. was a recipient fellow of the Generalitat de Catalunya.

Departament de Química Orgànica and IBUB, Facultat de Química Universitat de Barcelona, Martí i Franquès 1-11, 08028 Barcelona, 20 Spain. Fax: +3493339787; Tel: +34934021263; E-mail:

anna.grandas@ub.edu

Abbreviations. $\quad \mathrm{ACN}=$ acetonitrile, $\quad \mathrm{CNE}=2$-cyanoethyl, $25 \mathrm{DCM}=$ dichloromethane, $\mathrm{DIPC}=N, N^{\prime}$-diisopropylcarbodiimide, $\mathrm{DMAP}=N, N$-dimethylaminopyridine,

$\mathrm{DMF}=N, N-$ dimethylformamide, $\quad \mathrm{Dmf}=$ dimethylaminomethylene (dimethylformamidine), $\mathrm{DMT}=4,4^{\prime}$-dimethoxytrityl, $\quad \mathrm{EDC}=\mathrm{N}$ ethyl- $N$ '-(3-dimethylaminopropyl)-carbodiimide $\cdot \mathrm{HCl}$, LCAA${ }_{30} \mathrm{CPG}=$ long chain aminoalkyl controlled pore glass beads, $\mathrm{Pac}=$ phenoxyacetyl, $\quad \mathrm{TCA}=$ trichloroacetic $\quad$ acid, TEA=triethylamine, $\mathrm{THF}=$ tetrahydrofuran.

\section{References}

351 (a) R. L. Juliano, X. Ming and O. Nakagawa, Acc. Chem. Res., 2012, in press (DOI: 10.1021/ar2002123); (b) Y. Singh, P. Murat and E. Defrancq, Chem. Soc. Rev., 2010, 39, 2054-2070; (c) J. Kalia and R. T. Raines, Curr. Org. Chem., 2010, 14, 138-147.

2 C. D. Juby, C. D. Richardson and R. Brousseau, Tetrahedron Lett., 1991, 32, 879-882.

3 M. R. Putta, F.-G. Zhu, D. Wang, L. Bhagat, M. Dai, E. R Kandimalla and S. Agrawal, Bioconjugate Chem., 2010, 21, 39-45.

4 J. Kalia and R. T. Raines, Bioorg. Med. Chem. Lett., 2007, 17, 62866289.

455 A. D. Baldwin and K. L. Kiick, Bioconjugate Chem., 2011, 22, 19461953.

6 B.-Q. Shen et al., Nat. Biotechnol., 2012, 30, 184-189.

7 H. Eberhard, F. Diezmann and O. Seitz, Angew. Chem. Int. Edit., 2011, 50, 4146-4150.

${ }_{50} 8$ H. Lönnberg, Bioconjugate Chem., 2009, 20, 1065-1094.

9 H. C. Kolb, M. G. Finn and K. B. Sharpless, Angew. Chem. Int. Edit., 2001, 40, 2004-2021.

10 (a) A. Chollet, Nucleosides \& Nucleotides, 1990, 9, 957-966; (b) C.H. Tung, M. J. Rudolph and S. Stein Bioconjugate Chem., 1991, 2, 464-465; (c) Y. Uchiyama, H. Inoue, E. Ohtsuka, C. Nakai, S. Kanaya, Y. Ueno and M. Ikehara, Bioconjugate Chem., 1994, 5, 327332; (d) J.-P. Bongartz, A.-M. Aubertin, P. G. Milhaud and B. Lebleu, Nucleic Acids Res., 1994, 22, 4681-4688; (e) J. G. Harrison and S. Balasubramanian, Nucleic Acids Res., 1998, 26, 3136-3145; (f)
Sci. USA, 1999, 96, 91-96; (g) F. Kukolka and C. Niemeyer, Org. Biomol. Chem., 2004, 2, 2203-2206; (h) B. A. R. Williams and J. C. Chaput, in Current Protocols in Nucleic Acid Chemistry, ed. M. Egli, P. Herdewijn, A. Matsuda and Y. Sanghvi, John Wiley \& Sons, USA, 2010, unit 4.41, pp. 4.41.1-4.41.20.

11 (a) J. D. Gregory, J. Am. Chem. Soc., 1955, 77, 3922-3923; (b) P. O. Tawney, R. H. Snyder, R. P. Conger, K. A. Leibbrand, C. H. Stitelerand and A. R. Williams, J. Org. Chem., 1964, 26, 15-21.

12 A. Sánchez, E. Pedroso and A. Grandas, Org. Lett., 2011, 13, $4364-$ 4367.

13 (a) J. Casals, L. Debéthune, K. Alvarez, A. Risitano, K. R. Fox, A. Grandas and E. Pedroso, Bioconjugate Chem., 2006, 17, 1351-1359; (b) S. Zaramella, E. Yeheskiely and R. Stromberg, J. Am. Chem. Soc., 2004, 126, 14029-14035; (c) S. Peyrottes, B. Mestre, F. Burlina and M. J. Gait, Tetrahedron, 1998, 54, 12513-12522; (d) C. N. Tetzlaff, I. Schwope, C. F. Bleczinski, J. A. Steinberg and C. Richert, Tetrahedron Lett., 1998, 39, 4215-4218.

14 A. Sánchez, E. Pedroso and A. Grandas, Bioconjugate Chem., 2012, 23, 300-307.

8015 R. T. Pon, in Current Protocols in Nucleic Acid Chemistry, ed. S. L. Beaucage, D. E. Bergstrom, P. Herdewijn and A. Matsuda, John Wiley \& Sons, Inc., USA, 2000, unit 3.2, pp. 3.2.1-3.2.23. 